United States Department of Agriculture

Agricultural Research Administration

Bureau of Entomology and Plant Quarantine

\title{
COLD STORAGE TO CONTROL THE CIGARETTE BEETLE IN CIGAR TOBACCOS
}

\author{
Joseph N. Tenhet and Clarence O. Bare $\underline{1,2 /}$ \\ Division of Stored Product Insect Investigations
}

The control of the cigarette beetle (Lasioderma serricorne $(F$.$) ) in$ cigar tobacco by fumigation has never been entirely satisfactory. The fumigated tobacco must be held in storage until all trace of the fumigant is gone. With the widespread use of storage at subzero temperatures for the preservation of other products, cigar manufacturers have become interested in the possible use of such storage for the control of the cigarette beetle. Swingle (1) showed that, although all stages of this insect could be killed in 60 hours with a temperature of $15^{8} \mathrm{~F} ., 31 / 2$ to $51 / 2$ days were required for the centers of bales of tobacco stored at $10^{\circ}$ to cool to $15^{\circ}$. Cigar manufacturers have stated that a 3 -day exposure in storage at subzero temperatures would be practical, if effective. Therefore, experiments were undertaken at Lancaster, $\mathrm{Pa}$., in 1950 to answer three questions:

Will exposure to very low temperatures injure cigar tobaccos?

At very low temperatures how rapidly will the temperature fall at different depths in the tobacco.

At different depths in the tobacco how quickly will all stages of the cigarette beetle be killed?

All the tobacco used in these experiments had been thoroughly sweated and was in good condition. It was in cases approximately 30 inches wide, 30 inches deep, and 42 to 48 inches long, and weighing approximately 400 pounds.

Test lots of 25 cigarette beetles--4 lots of each stage (adults, eggs, larvae, and pupae) per case--were placed in the center of each case or at various depths in the tobacco. Each lot was confined in a perforated carboard pillbox.

if lise work uron which this paper is based was conducted while the authors were in the Division of '1 ruck Crop and liarden Ir.sect Investigations.

2/ The authors express their appreciation to the General Cigar Company and the Goodling Electric Company for their assistance in these experiments. 


\section{Experiment 1}

In the first experiment five cases of tobacco were placed in cold storage at approximately $-10^{\circ} \mathrm{F}$. In three of the cases the tobacco was in medium order, in one case it was dry, and in one case was soft. The term "order" refers to a condition of the tobacco leaf in which it contains sufficient moisture to be pliable and handled readily without breaking. In these experiments the tobacco in medium order contained approximately 15 to 16 percent of moisture, dry tobacco contained less moisture (usually about 14 percent), and soft tobacco more moisture (usually about 17 percent).

The capacity of the cold-storage chamber was approximately 3,000 cubic feet, and the cold air was circulated in the chamber. Test lots of cigarette beetles were placed in the center of each case.

At the beginning of the experiment the temperature of the tobacco was $72^{\circ} \mathrm{F}$. Later the temperatures in the cold-storage room and of the tobacco at the center of a case were as follows:

$\begin{array}{cc}\text { Cold-storage room } & \text { Tobacco } \\ -10^{\circ} \mathrm{F} . & 26^{\circ} \mathrm{F} . \\ -8 & 8 \\ -8 & 4\end{array}$

Unfortunately, thermocouples were not available for this experiment. The temperature readings, obtained by means of a long metal-jacketed thermometer thrust into the tobacco, were thought to be unreliable, because in an air temperature of $-10^{\circ} \mathrm{F}$. it is possible that the cold would be carried into the bulb of the thermometer by the metal jacket.

After 4 days the cases of tobacco were removed from cold storage and the insects were removed and examined. Mortalities of adults and larvae were recorded after 3 to 4 hours and incubation of eggs and emergence of adults after 3 to 6 days. Table 1 shows that only a few of the test insects survived, except in the soft tobacco.

Table 1.--Percent survival of cigarette beetles in the center of cases of cigar tobacco exposed for 4 days to approximately $-100 \mathrm{~F}$.

\begin{tabular}{|c|c|c|c|c|c|}
\hline $\begin{array}{l}\text { Type of } \\
\text { tobacco }\end{array}$ & $\begin{array}{l}\text { Moisture con- } \\
\text { dition of tobacco }\end{array}$ & Adult & Larvae & Pupae & Eggs \\
\hline \multirow[t]{2}{*}{ Wisconsin binder } & Dry & 0 & 0 & 0 & 0 \\
\hline & Medium order & 0 & 2 & 0 & 0 \\
\hline Pennsylvania filler & Soft & 41 & 93 & 40 & 7 \\
\hline Connecticut binder & Medium order & 8 & 18 & 1 & 0 \\
\hline Havana seed binder & -do.- & 0 & 0 & 0 & 0 \\
\hline $\begin{array}{l}\text { Pennsylvania filler } \\
\text { (check) }\end{array}$ & -do.- & 98 & 100 & 100 & 96 \\
\hline
\end{tabular}


Leaf-tobacco experts carefully examined all the tobacco several days after it had been removed from cold storage. They concluded that none of it had been adversely affected by exposure to cold. All the tobacco was dry and hard when first removed from the cold room, but as it warmed up it absorbed moisture from the air. After 2 to 4 days the tobacco had returned to normal summer temperature, and was at least in as good condition as before it was exposed. Some of the dry tobacco was slightly improved, as it had picked up a little more moisture.

\section{Experiment 2}

In the second experiment 10 cases of tobacco were placed in cold storage at approximately $-10^{\circ} \mathrm{F}$, as described in the first experiment. Four of the cases were of Pennsylvania filler, four of Wisconsin binder, and two of Connecticut binder. All the tobacco was in medium order except one case of Pennsylvania filler, which was soft. Five cases, including the one of soft tobacco, were held in cold storage for 3 days, one case was held for 4 days, one for 5, and three for 6 days. In two cases thermocouples were placed at 5, 10, 15, and 21 inches from the approximate center of one end. The thermocouple 21 inches from the end was at approximately the center of the mass of tobacco. One of these cases was the soft tobacco held in cold storage for 3 days, and the other case was in medium order and held for 6 days.

Test lots of the various stages of the cigarette beetle were placed in each case- $-4,8,12$, and 16 inches deep into the tobacco from the approximate center of one end. Check lots were placed at the same locations in four cases of the same types of tobacco, and held at summer storage temperature--about $80^{\circ}-850 \mathrm{~F}$. The temperature of all the tobacco at the beginning of the experiment was $84-86^{\circ} \mathrm{F}$.

The decreases in temperature of the tobacco at different deptns in the case are shown in figure 1. At a depth of 5 inches only 1 day was required for the tobacco temperature to fall to $0^{\circ} \mathrm{F}$., as compared with more than 3 days at 10 inches and more than 5 days at 15 inches. At 21 inches, in the center of the case, the temperature dropped a little more slowly than at 15 inches during the first 4 days, but by the sixth day the temperatures at these two locations were the same.

Table 2 shows that a 3-day exposure killed all insects at the 4-inch depth, and also at the 8-inch depth in the tobacco of medium order. As in the first experiment, an appreciable percentage of larvae and adults survived at this 8 -inch depth in the soft tobacco. After 4 days' exposure mortality was complete at both the 12 - and 16-inch depths in all tobacco. 
Table 2.--Percent survival of cigarette beetles at different depths in cases of cigar tobacco held for 3 days in cold storage at approximately $-10^{\circ} \mathrm{F}$.

\begin{tabular}{|c|c|c|c|c|c|}
\hline $\begin{array}{c}\text { Moisture condition } \\
\text { of tobacco }\end{array}$ & $\begin{array}{c}\text { Depth of insects } \\
\text { in tobacco }\end{array}$ & Adults & Larvae & Pupae & Eggs \\
\hline & Inches & & & & \\
\hline \multirow[t]{4}{*}{ Medium order } & 4 & 0 & 0 & 0 & 0 \\
\hline & 8 & 0 & 0 & 0 & 0 \\
\hline & 12 & 0 & 8 & 0 & 0 \\
\hline & 16 & 0 & 7 & 0 & 0 \\
\hline \multirow[t]{4}{*}{ Soft } & 4 & 0 & 0 & 0 & 0 \\
\hline & 8 & 56 & 48 & 4 & 0 \\
\hline & 12 & 100 & 60 & 36 & 2 \\
\hline & 16 & 48 & 80 & 44 & 5 \\
\hline \multirow[t]{4}{*}{ Medium order (check) } & 4 & 100 & 98 & 100 & 100 \\
\hline & 8 & 100 & 100 & 89 & 98 \\
\hline & 12 & 100 & 98 & 95 & 100 \\
\hline & 16 & 100 & 98 & 96 & 98 \\
\hline
\end{tabular}

\section{Experiment 3}

In the third experiment four cases of tobacco were placed in a commercial cold-storage plant at $-20^{\circ} \mathrm{F}$. for 3 days. The air in this plant was not circulated as in the other tests. One case was dry, two cases were in medium order, and one was soft. In three cases, thermocouples were placed 4, 8, 12, and 16 inches from the approximate center of one end. Test lots of all stages of the cigarette beetle were placed in each case, as in the preceding experiment. Check insects were held at room temperature $\left(75^{\circ}-80^{\circ}\right)$.

The temperature decrease was slightly greater in the dry tobaccc than in the tobacco of medium order, and slightly less in the soft tobacco (fig. 2).

The effect of the moisture content of the tobacco on the mortality of test insects is shown in table 3 . All the insects were killed at the 4 -inch depth. At the 8-inch depth there was no survival in dry tobacco, negligible survival in tobacco in medium order, and appreciable survival, especially of larvae, in soft tobacco. At the 12- and 16-inch depths survival increased with the moisture content of the tobacco. 
Table 3.--Percent survival of cigarette beetles at various depths in cases of cigar tobaccos of different moisture content, held for 3 days in commercial cold storage at $-20^{\circ} \mathrm{F}$.

\begin{tabular}{l|c|r|r|r|r}
\hline $\begin{array}{l}\text { Moisture condition } \\
\text { of tobacco }\end{array}$ & $\begin{array}{c}\text { Depth of insects } \\
\text { in tobacco }\end{array}$ & Adults & Larvae & Pupae & Eggs \\
\hline \multicolumn{1}{l}{ Inches } & & & & \\
Dry & 4 & 0 & 0 & 0 & 0 \\
& 8 & 0 & 0 & 0 & 0 \\
& 12 & 8 & 16 & 4 & 0 \\
& 16 & 16 & 44 & 60 & 8 \\
Medium order & 4 & 0 & 0 & 0 & 0 \\
& 8 & 0 & 4 & 0 & 0 \\
& 12 & 48 & 50 & 32 & 11 \\
Soft & 16 & 34 & 59 & 64 & 93 \\
& 4 & 0 & 0 & 0 & 0 \\
& 8 & 0 & 68 & 24 & 20 \\
& 12 & 100 & 76 & 52 & 98 \\
& 16 & 100 & 100 & 82 & 100 \\
Medium order (check) & 4 & 100 & 96 & 100 & 100 \\
& 8 & 100 & 92 & 100 & 100 \\
& 12 & 100 & 96 & 100 & 100 \\
& 16 & 100 & 92 & 100 & 100 \\
\hline
\end{tabular}

\section{Summary}

Three experiments on the control of the cigarette beetle (Lasioderma serricorne (F.)) in tobacco exposed to subzero temperatures were conducted at Lancaster, $\mathrm{Pa}$., in 1950. In the first experiment all stages of the beetle were placed at the center of tobacco held in cold storage chambers at approximately $-10^{\circ} \mathrm{F}$., and in the second experiment they were placed at various depths in the tobacco. In both these experiments the air was circulated. In the third experiment, the insects were placed in tobacco in a commercial cold-storage plant at $-20^{\circ} \mathrm{F}$. in which the air was not circulated.

The low temperatures did not injure any of the tobacco. 
In cases stored at $-10^{\circ} \mathrm{F}$. only 1 day was required for the tobacco temperature at a depth of 5 inches to fall to $0^{\circ} \mathrm{F}$., or compared with more than 3 days at 10 inches and more than 5 days at 15 inches.

The mortality of the insects depended upon the circulation of air in the storages and upon the moisture condition of the tcbacco. Exposure to $-10^{\circ} \mathrm{F}$. in circulated air was more effective than exposure to $-20^{\circ}$ in still air. For tobacco of medium order a 3 -day exposure to $-10^{\circ}$ with the air circulated was as effective as fumigation in an atmospheric chamber. For soft tobacco an exposure of 4 to 5 days was necessary.

\section{Literature Cited}

(1) Swingle, M. C.

1938. Low temperature as a possible means of controlling the cigarette beetle in stored tobacco. U.S. Dept. Agr. Cir. 462, 8 pp. 


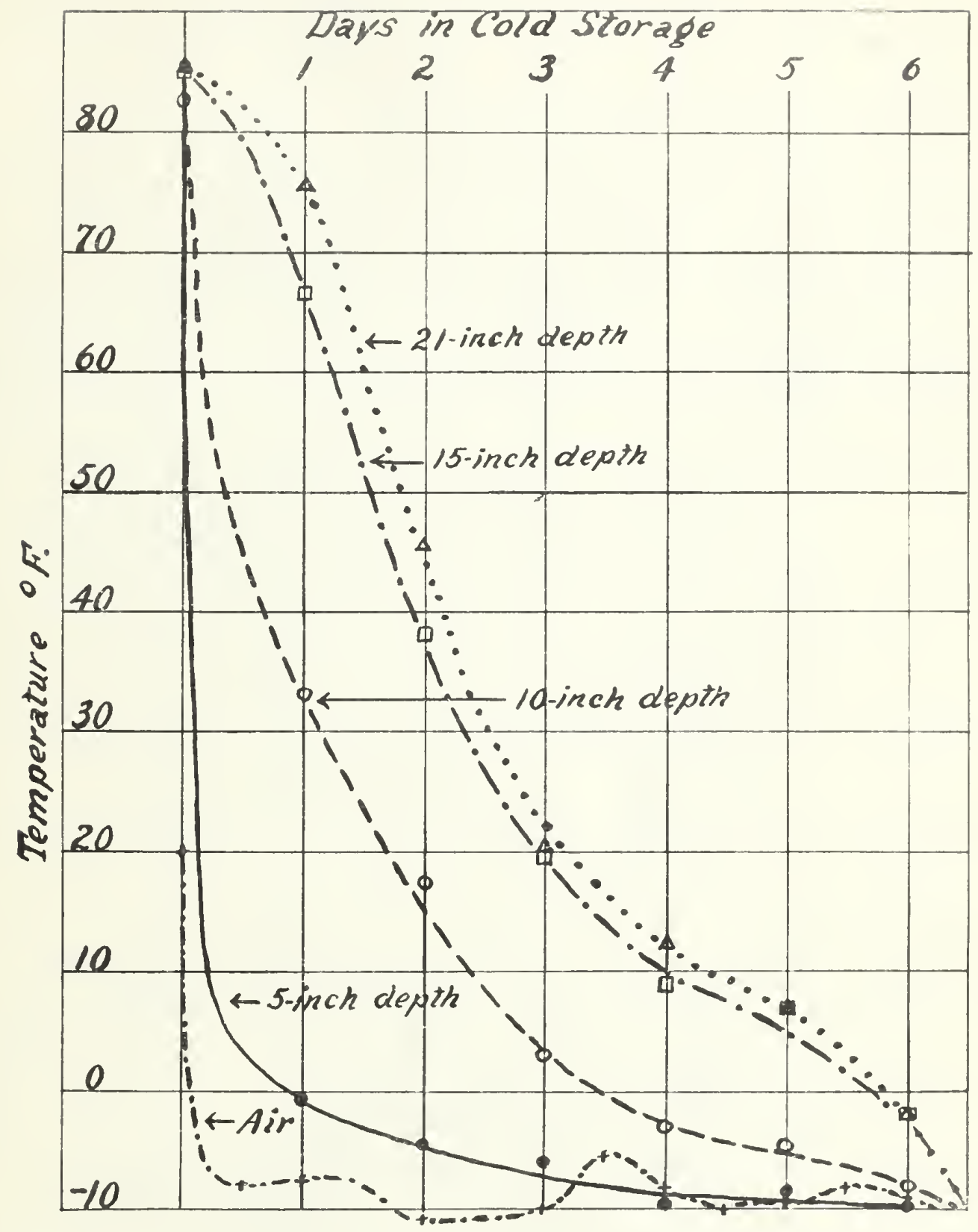

Figure 1.--Decreases in temperature at four depths in cases of cigar tobacco held in cold storage for 6 days at approximately $-10^{\circ} \mathrm{F}$. 


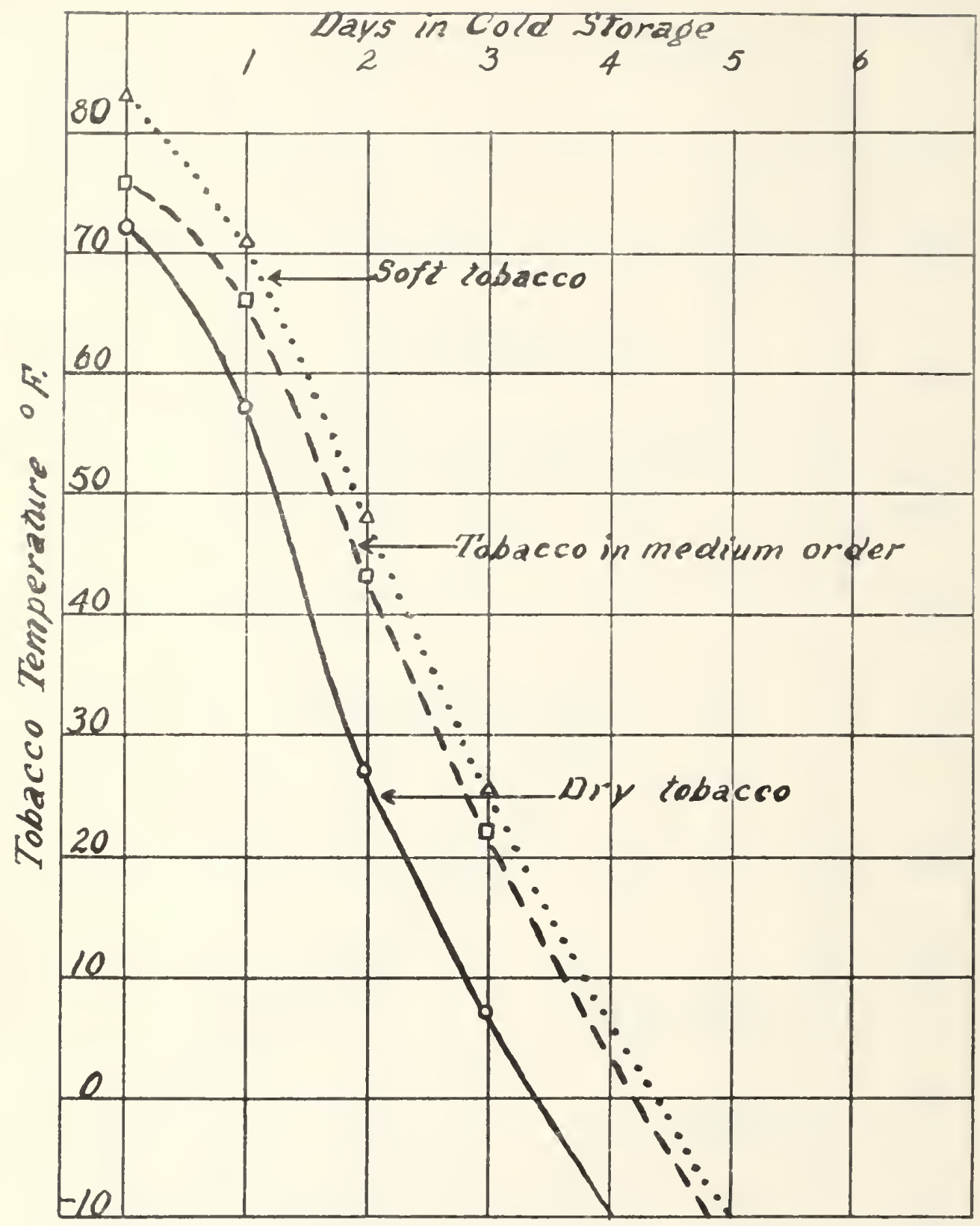

Figure 2.--Decrease in temperature at a depth of 16 inches in cases of cigar tobacco of different moisture content held in cold storage for 5 days at approximately $-10^{\circ} \mathrm{F}$. 